\title{
Simile As An Effective Literary Device in the Vietnamese-English Translation Equivalent
}

\author{
Nguyen Huu Chanh \\ Viet Nam National University, Ho Chi Minh City. Viet Nam \\ nguyenhuuchanh06@gmail.com
}

\author{
ARTICLE HISTORY \\ Received : 2021-05-21 \\ Revised : 2021-08-07 \\ Accepted : 2021-08-19
}

\section{KEYWORDS}

Simile

Translation training

Translation education

Literary work

Figure of speech

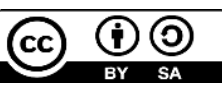

\begin{abstract}
Many Vietnamese writers have recognised the utility of literary devices to beautify the artistic features in written texts. Like other rhetorical devices, simile plays an essential role in bringing meaningful values close to the readers. The research aims at identifying the usage of simile in the translation equivalents between Vietnamese and English in De men phiеи lии ky and its translated version Diary of a cricket. From analysing 108 sentences by the descriptive qualitative research, the findings showed that (1) The high frequency of using the complete form of simile to express the figure of speech. (2) The imbalance in the translation rate between two languages and the most popular simile word of like usage in English translated text. (3) The variables of comparative words and themes used in the target text show the same meaning in the source text. Those conclusions shed light on the quality improvement on the target text, especially in both translator's training and further translation education.
\end{abstract}

\section{Introduction}

The translation is not an easy task, but translating from one language to another entirely different system is a big challenge. According to Nguyen (1997) in his research "Tieng Viet khong son phan", he described a Vietnamese sentence with the subject (chủ ngữ) producing a topic (đề) and the predicate (vị ngữ) making a comment (thuyết). The subject varies from nouns, pronouns, compound nouns, or noun phrases. The predicate is understood as a verb or verb phrase for example, Ba tôi là một cán bộ hưu trí. The translation process has enhanced its quality by analysing the nature of English and Vietnamese sentences and made more significant contributions to the translation industry. Regarding the study about the contrastive analysis between English and Vietnamese, Nguyen (1967) mentioned in his research about A contrastive grammatical analysis of English and Vietnamese in which sentences and grammatical points are carefully examined. To be specific, some dependents and independent clauses are introduced.

Translation in literary proses has been an increasing concern to the Vietnamese translator in recent years since it requires an in-depth knowledge of both languages when the texts are expressed in written form. The problem is the language system, namely English as an analytical language and Vietnamese as an inflectional one. The ultimate goal of the study is to figure out how the simile is applied by displaying some related studies. It compares the Vietnamese version of De men phieu luu ky and translated text of Diary of a cricket in terms of translation equivalents by giving some typical notes within the source and target text and finally illustrating some significant findings to the translator's training and translation education. In recent times, there has been more discussion about expressing a language in direct and non-direct ways. For the former, meanings can be understood through words and sentences, but for the latter, the underlying meaning should be put in a context following figures of speech (Li et al. 2010; Thahara, 2015; Azizah, 2019; Wisnita, 2019); De Mendoza Ibáñez, 2020; Nguyen, 2021). In literature, writers usually use figures of speech to show their ideas since they think about more than what a word infers to become a good author (Nguyen, 2021). The aspects of word sound are also a crucial factor that requires writers to consider. The sound has a significant impact on the literary text with well-chosen words because it strengthens a mood and becomes more forceful. When doing a translation process, prose with a successful and famous reputation domestic and internationally, a writer or author is professional enough to contribute the exact meanings into the target text. Translation does not mean rewriting a text but coveys an original meaning and suits the target culture that the author attempts to reach (Nguyen, 2021). Besides, the translator cannot always get in touch with the author, so discover the original culture. The translated version needs to be associated with words and meanings (Newmark, 1998) and agrees between two translations (Hassan, 2011). Hassan stated 
that the translator coined a platform to bridge the diversity of cultures and countries. By so doing, the two most important features are propositional and pragmatic issues. For the latter, the content of principles and theories aims at augmenting the text, and then the translation quality significantly improves.

A simile is a phenomenon that compares two opposite objects by using "like" or "as" in the sentence (Kandenan, 2017). This function word is the recognised point to express simile (Richards \& Schmidt, 2010; Azizah, 2019 \& Myers, 1994). Although there is no apparent difference between utilising like and as within a sentence, most studies mentioned like rather than as a figure of speech which creates a question about whether the existence of like and as a gap in simile happens. Writers use similes in their writings to show an object in a more meaningful idea. It is understood since it coins a strong impression on the readers. This figure of speech makes this comparison surprising though the two objects are different. The purpose of similes is to coin noticed pictures and make the readers more understanding about the line of the poem.

The application of stylistic devices is commonly used to achieve the human's purposes in a particular way. The language users need to be aware of the factors, including the choices of words and how they are applied within the appropriate contexts that constitute the whole idea. Those are expected as a gap that intends to be mentioned in the discussion. In literature, writers usually use figures of speech to show their ideas since they think about more than what a word infers to become a good author. There are many ways to define what a figure of speech is. According to Richards \& Schmidt (2010), it is concerned about "a word or phrase" in an exact scenario and implies a meaning altogether different from the original words exposed. A sentence can be understood either literal and figurative meaning. For the latter, the writer aims at creating a more robust image for the readers.

As stressed previously, a translation technique between two languages is a powerful tool frequently employed in acquiring the original meanings; therefore, there is no question why the issue has been brought into the research field by some scholars worldwide. Wisnita (2019) had surveyed 40 questions understanding and using the simile in language learning with $60,92 \%$. Besides, the evaluation of the current instructors has also been added, thanks to this investigation. However, the paper just covered part of the simile, not more specific details in the literary work and how it could be transferred to another language other than English, leading the researcher to explore the veiled area. Another research, namely the technique of simile in the novel by Thahara (2015), carried out with descriptive qualitative research, showed 14 translation ways utilised in the novel, and literal translation became predominant when translating from English to Indonesia. From the findings of this study, it is necessary to know whether the Vietnamese language was also applied in the same procedure of translation or not. In other words, whether the communicative and cognitive functions were mentioned in the Vietnamese language. Hence, the paper was implemented to meet the wonders mentioned above.

Most importantly, in Nguyen Dang Liem's massive study, many pieces of research analysed English and the Vietnamese language features. According to his study (in Volume 1) in 1966 about the English grammar using the tagmemic and transformational approach. He showed his explanations in kernel sentences, known as the grammatical hierarchical level's strings in simple, compound, and complex sentences. The words within the Vietnamese language focus on word order and function words. This understanding opens a new direction to make comparisons from a single meaningful unit to an essay. The subsequent analysis about grammatical points (in Volume 3) in 1967 figured out that the construction in Vietnamese and English sentences is the same. The grammar also affects in terms of necessity but not sufficiency in writing an English text. When considering contrastive analysis, it is vital to present the deep structure, and surface structure stated in the sentence.

Moreover, he continuously researched phonology in two languages (in Volume 4) in 1970 and concluded that the linguistic features in contrastive analysis need to be centred, which contributed to the whole studies in two languages. In addition to the mentioned studies, there were also several researchers to determine detailed similarities and differences of the points as mentioned earlier, namely the analysis of proverbs relevant to plants applied in teaching career conducted by Bui Thi Phuong Thao (2011), the research of negative sentences in the basic structure, starting from the formulations of L2 and then their equivalent in L1, by Chau Thi Khanh Linh et al. (2017). Frank Nhat Trinh's study in 2002 mentioned the English and Vietnamese collocations by figuring out different subtlety dimensions, the variations, and details of mixtures of words in two languages. Vo Tran Mong Thu (2010) study noted that Vietnamese people do not frequently use noun phrases like English, especially in legal writing texts. Furthermore, the study A Contrastive Analysis: Idioms of Comparison in English and Vietnamese by Nguyen Dinh Tuan illustrated the similarities and differences between two languages by displaying several words in the shape of idioms with two essential features: semantic and structural. Every culture is not distinguished and unique, creating a gap to perform the same viewpoints (Nguyen, 2011 \& Bui, 2011). Thanks to that biological and cultural characteristics, the Vietnamese and English sometimes have similar observations through concepts and matters. This study is closely associated with the researcher's study since the illustrations compare English and Vietnamese idioms. The two objects are compared: 
Thing - Thing, Person - Thing, Thing- Person, Person Person.

Moreover, the study named A contrastive analysis of Passive Voice in English and Vietnamese by Nguyen Thi Diem Quynh (2010) showed that Vietnamese people prefer sentences inactive while English tend to use more passive forms. The sentences emphasise the fact, the action, or its result, so the recipients are mainly focused. To understand Vietnamese sentences, it is vital to depend on the semantic meaning and grammatical features. Besides, the English subjects agree with the verbs while the Vietnamese ones do not.

From the points mentioned above, this study aims to research the translation equivalent in Vietnamese English under the book De men phieu luu ky by To Hoai, a very well-known book and its translated version by Dang The Binh, published by Kim Dong Publishing House. For children to adults who are always a big fan of To Hoai, De men phieu luu ky is one of the best well-known literary works suggested for those who enjoy their childhood memory. With a simple but attractive writing style, To Hoai always reminds every person of lively imagining their past with sweet and unforgettable things. Each word touches the reader's heart since those are a piece of their past life. Once the study was conducted successfully, new translated ways of thinking with the focused formulations and themes were discovered, which contributed significantly to the translator techniques when doing a translation job. The study concentrates on improving the translation process's quality of the target text in English from a Vietnamese version. Therefore, this study primarily focuses on (1) looking at an overview of the background of the study with like and as (2) checking that whether using the simile is a valuable figure to understand the meaning in English (3) reconfirming the way of translating English language vocabulary effectively. A simile is collected and tested by looking at the Vietnamese words and their English translations in the book to compare and contrast based on the usages of Simile in two versions.

\section{Method}

In order to mainly focus on using the simile to enhance the writers' ability and bring the equivalent ideas in the source text into the target language, the books were used, namely De men Phieu luu ky and its translated version - Diary of a Cricket.

Simile is collected and tested by looking at the Vietnamese words and their English translations in the book to compare and contrast in all dimensions of the use of simile in English literary work. The author himself has read and consulted many books in some Vietnamese publishing houses and internet search for references to select the sources and materials.

The study employed qualitative research in which the data is analysed to understand the phenomena
(Hollis, 1994) since this type is expected to gain indepth knowledge of the data and avoid the early judgment during the data analysis (Atieno, 2009). According to Beidel, Frueh, \& Hersen (2014), the method aims to make the data more straightforward but still preserve the level of difficulty of the text. It is necessary to review the previous knowledge to support the validity and reliability of the current study (Cropley, 2019).

Therefore, the key objective of this research is to investigate a description of the study context through simile; explore whether the judgments of this rhetorical device is a reasonable way to comprehend English words and interpret English vocabulary appropriately. Moreover, all the words in the description are critically described to substantially contribute to the contextual context, enhance the speaker's skills, and recommend improved techniques for interpreting words in various situations. The accuracy of the analysis is also clearly seen. The data will then be evaluated in groups, tables in which figures such as proportion and occurrence counts will be measured.

With the detailed and clearly stated evidence of data and active work spirit, this study is assured to bring the best attempt from the researcher: (1) The story and writer are well-known not only in Vietnam but also around the world. Besides, the writer has already possessed over 100 short and long stories with much experience. (2) The translator has much experience to bring the most corrected version from the source text to the target text since he has also had some publications in English translation. (3) The publishing house has been long with identified reputation nationwide. This publishing house has been established in 1957 and is prestigious in serving books for children and introduce Vietnamese culture to the world. According to the data from the publishing house, the book has already begun its first publication in 80 years with numerous reprints and translations of up to 20 languages. Hence, the researcher hopes that the study will give an accurate outlook about the problem addressed.

\section{Findings}

From the data taken from the book De men phieu luu ky and its translated version, Diary of a cricket, and the methodology described above, the following points illustrate how the Vietnamese language was expressed in the English version with simile's application. There were three areas to be addressed.

First, the formulation of simile in both versions was presented by giving two pie charts, one in Vietnamese comparison and the other in the target language. Table 3.1 added in this section aimed to illustrate each investigated element's order to support the typical rule used in the original and translated version. Secondly, Table 3.2 in this section showed the distribution of Vietnamese and English sentences to serve as evidence within the study, while Figure 3.3 displayed the 
number of sentences translated from the source to the target language. Finally, Figure 3.4 showed the variables of words used in the target text, and Figure 3.5 mentioned the most frequent theme that simile was applied in translation equivalent.

\subsection{The Structural Feature of using simile in two languages}

Table 3.1 The arrangement of the simile's form

\begin{tabular}{ccc}
\hline Former & Comparative words & Latter \\
\hline $\mathrm{X}$ & Like or else & $\mathrm{Y}$ \\
\hline
\end{tabular}

As the data coding mentioned, there were three sets of comparisons: $\mathrm{X}$ is the left part or components of the comparative word (like, or else), while $\mathrm{Y}$ is the latter part. This structure was set up as follows:

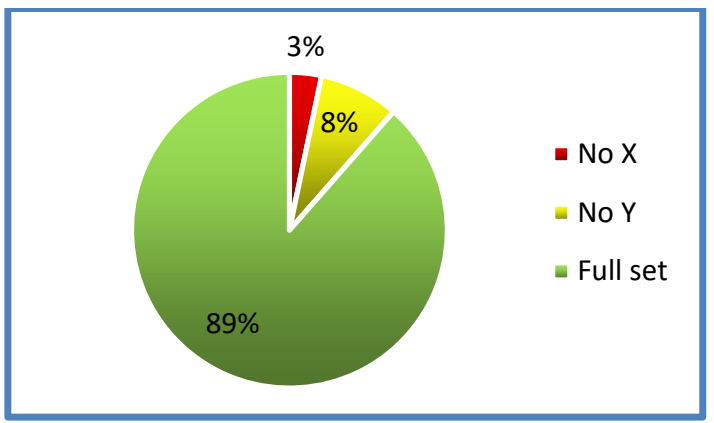

Figure 3.1 Components (X, Y) within the sentences in the Vietnamese version

For figure 3.1, the writer (To Hoai) utilised the simile in his original book while, for figure 3.2, this figure of speech was expressed. When discussing the distribution of the simile in the original text of De men phieu luu $k y$, it was noted that the proportion of $\mathrm{X}$ deletion is $8 \%$, while the sentence with Y's omission accounted for $10 \%$. The remaining figure of complete comparison ranked first $82 \%$. The data meant that people tended to use the complete structures of simile to express the whole meaning.

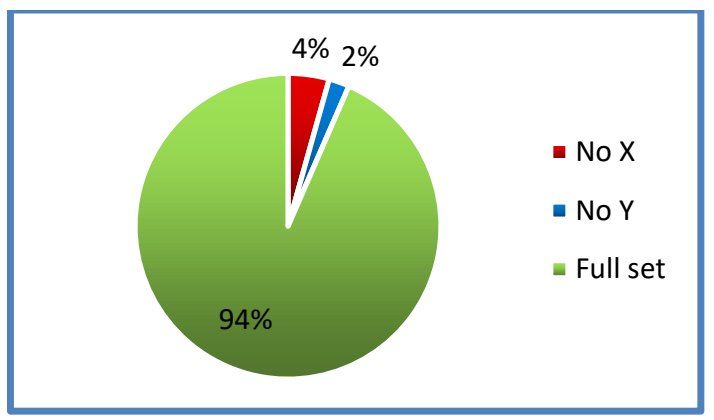

Figure 3.2 Components (X, Y) within the sentences in the English version

Regarding the translated version, the result also stayed the same as the original text, in which the complete set of similes was preferred. To be more specific, it was noted that the percentage of $\mathrm{X}$ deletion is $4 \%$, while the sentence with Y's omission accounted for $2 \%$. The remaining figure of complete comparison ranked first $94 \%$. From the data, it meant that the Vietnamese and English languages used simile in a complete form.

\subsection{The Comparison between Translated Sentences in Two Languages}

Table 3.2. The number of investigated sentences

\begin{tabular}{ccc}
\hline Types & Response count & Per cent response \\
\hline Vietnamese & 61 & $56 \%$ \\
English & 47 & $44 \%$ \\
\hline
\end{tabular}


To ensure the validity and reliability of the data analysis, the number of limited sentences with simile were investigated to show the balance in the data. There were 108 sentences in the investigation. Of the
61 sentences in Vietnamese and 47 sentences in English were investigated in this study, the percentage is $56 \%$ and $44 \%$, respectively, to calculate the equality of the two versions.

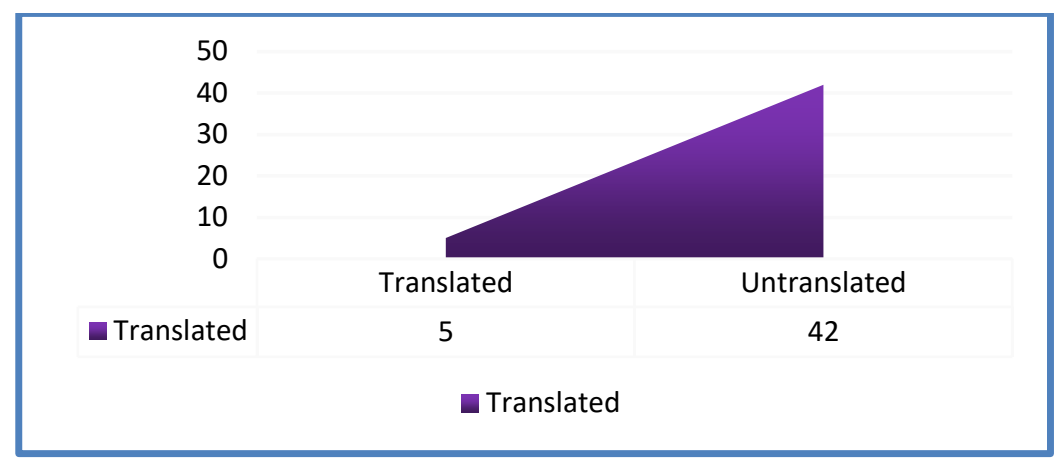

Figure 3.3 Translation rates between English and Vietnamese version

The number of translated sentences was limited during the data analysis, which was displayed in the chart ( 5 sentences) compared to the 42 untranslated sentences, accounting for nearly $90 \%$ of untranslated sentences. Since the characteristics of this comparison are the similarities and differences in Vietnamese and English, the translation equivalent was mainly focused. Of 47 investigated sentences, the matching sentences were just 5, showing the low possibility of using simile equivalent in two versions.

\subsection{The Comparative Words and Themes Utilised in the Target Text to Express Simile in the Vietnamese Language}

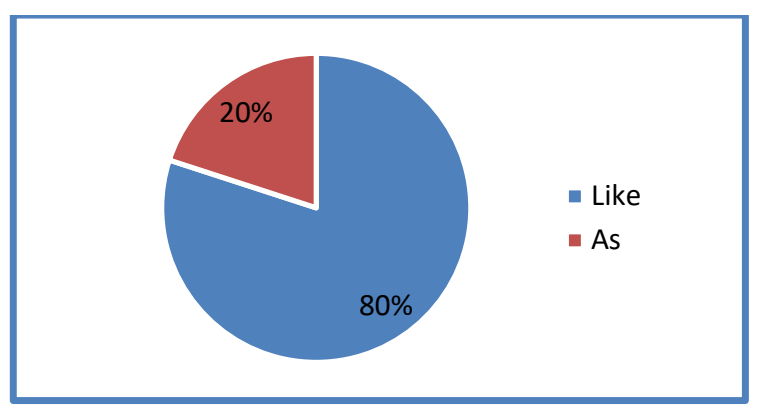

Figure 3.4 Comparative words utility in the context

Regarding the expression of simile, the were some types, namely, like and as. Those variables were used in English, but the Vietnamese version stated the same meanings, which are counted to contribute to the overall results. There were many illustrations for this type, but the high possibility of using like was predominant, accounting for $80 \%$. The following percentages were as with $20 \%$. The English translator preferred to use like in comparisons to express the simile in Vietnamese. This shed light on how simile was translated in Vietnamese and English so that more and more translators utilised this word in the translation process.

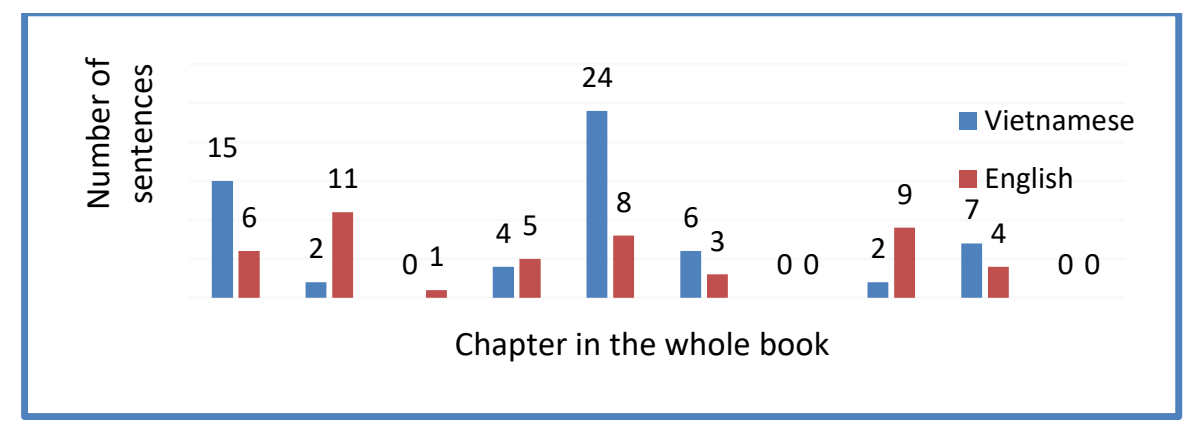

Figure 3.5 Simile sentences distribution in each chapter 
As illustrated in Figure 3.5, the blue and red columns were put in pairs from chapter 1 until 10. In chapter 3 and 7, there were rarely limited or almost no simile within the content, namely $0-1$ and $0-0$, respectively. Besides, the sentences with simile were not equal between Vietnamese and English. For example, there were 24 sentences in Vietnamese, but only eight sentences in English consisting of simile. Chapter 1 consisted of 15 in the source text but only 6 in target one. Hence, the chapter distribution in English and Vietnamese were not equivalent. In other words, the simile in chapter 5 ranks first.

There are 108 sentences counted in De men phieu luu ky and Diary to a cricket. The figure of the speech is delivered unevenly within the chapters. Regarding the content, the chart showed that the concentration was on the first and fifth chapters. The finding stated that the description of a cricket with independence when it was young and the unforgettable story during its lifetime present more simile than any other content. Besides, when the cricket got problems with food and water during its adventures, it realised more value in life.

\section{Discussion}

As stated in the findings, the result reconfirmed that the power of simile in the literary work, which has already been mentioned by Li et al. (2010); Thahara (2015); Azizah (2019); Wisnita (2019); De Mendoza Ibáñez (2020) in their previous study, so this would suggest the typical figure of speech that the translators would use in their professional work. What is more, there are some of the points to address over from the study. Firstly, both the writer (To Hoai) and translator (Dang The Binh) aims at conveying the correct and meaningful ideas from the source to the target language. The translator and author's ultimate purpose is to embed the aesthetic function and sometimes creativity in their writing, which can be mentioned surprisingly.

This feature is agreed with Pierini (2007) when he carried out the study about simile itself. The explanation here is understandable since it can cause misunderstandings about discussing the same images or features but holding contradicting viewpoints. That is why the study also agrees with Larson (1984) that something is hardly translated literally. Besides, when translating to a foreign language, ways of thinking need to be considered to control the learners' using words (Geng \& Wei, 2015; Hermans, 2003; Newmark, 1989). This process is clearly described in translation in any type by using contrastive analysis, which means predicting, describing, contrasting, and selecting the way we analyse the story. According to Fisiak (1981), contrastive analysis was defined as "a sub-discipline of linguistics concerned with comparing two or more languages or subsystems of languages to determine both the differences and similarities between them". De men phieu luu ky and Diary to a cricket are from two language systems that create a gap of understanding and transferring, but they still have shared points that connect to the other parts of the world.

Secondly, the author and translator have the same ways to use the forms of simile no matter of the language system, an inflectional or analytical one. In other words, the missing of any of the two parts are mostly not frequently accepted. Hence, this suggests another rule to use the simile in the literary process. Besides, the most beneficial feature when the complete set of simile is used in both languages is the expressions of the mentioned object, since it possesses the ideas mentioned, a means to transfer, and an indicator of the target ideas emphasised. This view is also agreed with Pierini (2007). In addition, for the grammatical structures, one of the essential components to produce a well-translated text is using suitable grammar structures. Translating requires a wide range of knowledge of structures with strict rules. Within a sentence, articles, adjectives, nouns, verbs, adverbs, tenses, etc., are combined in several ways, so they must be based on specific and default grammatical frames. Translating without context caused several limitations in the target text (Li et al., 2010). Some of the semantic and stylistic equivalences are not preserved. The translation process needs to be put in a particular context to arise the special terms and ideas that enable translators to be more straightforward to catch the underlying meanings of the text. That is the reason why word and choices of word meanings are also a noted point. When translating, it is compulsory to obtain the right words as they play a crucial role in conveying the source text's original meanings. Regarding the translating styles, including free, literal, and literary, the skills and performances in word selection are critical when dealing with complicated texts.

Secondly, from the statistics, not all the sentences (Vietnamese), including simile, are translated with the same comparison in the target language (English), which means that each language has its way to express simile although this figure of speech is used in two languages. This finding suggests that the simile's definition is sometimes not the same between two languages due to the cultural and historical features. The ultimate goal here is to preserve the figurative meanings from each language system. The reason for the above point is from the study of Sam \& Catrinel (2006); Kendenan (2017); Carston \& Wearing (2011), and Song (2020). Sometimes, the simile is confused with metaphor in some cultures since they hold the functions of comparisons. In other words, an image or idea means one thing in a particular culture but refers to another thing in different cultures. However, with the findings in this study, the simile is precisely determined through the comparison marker "like" so that no more confusion is left. In addition, when it comes to the frequency of like and as in the Vietnamese and translated text, the result has already illustrated the higher possibility to use like within the translated 
version. As usual, the two-letter word is prefered with the shorter time to write, but it contrasts this view. With three main functions, including preposition, conjunction, and adverb, one usage is less than like (an adjective as well). In this way, the more the word like is mentioned in the translated text, the more meanings the story conveys. Since the readers from different cultures read the book, they need to consider an image or a scenario in how the Vietnamese characters think. Therefore, the advantage is understanding Vietnamese culture from spending time reading the book. The variation of like usage makes the readers aware of what simile is placed because not all the word like is functioned similarly.

Thirdly, the simile is only in some of the topics, namely in limited circumstances that require expressing the characteristics of the characters or intend to bring a lesson from a memorable story. This finding is entirely new since the researcher found no previous studies that take this into account. Hence, it suggests that the simile is easily applied in the themes with ups and downs emotions or doing something that takes time to complete. In order to do so, it is necessary to possess characteristics of language. For language characteristics, one of the two elements that constitute a sentence by English language standards is the meaning components of lexical items. It is frequently considered as a phenomenon of differences in a language.

From the discussion above, the paper has already gone through some of the significant findings that contribute to translating a literary work. The paper has found the status of current translation and given recommendations toward the translation techniques so that the translators themselves could apply for their careers.

When doing a translation process, a translator must activate the background knowledge with a figure of speech so that an idea is equally transmitted. This process is understood since Vietnamese is quite challenging to learn, especially for understanding semantics views in the literary process. The translator needs to research how to make an animal in the most creative way and even suitable to Vietnamese context, but foreign readers can still imagine in a complete view. He or she must choose the appropriate figure of speech, simile as an example, to do it successfully. Besides, culture varies from country to country, so the translator needs to study carefully before translating using a simile. For example, the readers can understand Vietnamese life with specific things like cricket and other animals in Vietnamese fields and rivers. Besides, cricket's characteristics toward life and nature are also expressed when an animal is personalised to overcome ups and downs. However, there are still some limitations that need to be taken. Since the number of investigated sentences are not big enough, the appropriateness in the macro scale is not entirely accepted. Secondly, the study is just only implemented in a book with a translator, whereas there are many other skilled and professional translators in Viet Nam. Those factors have left the researcher to continue his scientific research on this issue in his lifetime. For future studies, it is hoped that the other figures of speech are unveiled, namely metaphor, hyperbole, and personification. Currently, more and more Vietnamese texts are translated, so it is a must to have a standard rule to translate the texts effectively, which preserves the real message from the author. For all discussions above, the study determined some of the typical ways to improve the translated texts, in which some points are agreed upon and established new findings.

\section{Conclusion}

This study's predetermined purpose is to discover the noticeable features of simile when using in Vietnamese and applying under the translator's writing. The findings have illustrated the critical roles of using simile in the literary context. Although there are differences in the language system, Vietnamese and English also show the same functions to compare the literal and figurative meanings in different scenarios. However, when comparing the source text and English version, not all the Vietnamese sentences using simile are equally translated into English, which means that two languages have their writing styles to show the original meaning since the utility of simile depends on how the ideas are transferred. To do effective translation, the translators themselves must obtain the theoretical background and relevant knowledge of the subject. By doing so, the more we research and practice, the more refined the target text is. The above analysis generalises the functions of simile in Vietnamese literature and its translation. Having completed this translation helps us learn many things. Doing a translation not only includes translating each word by its meaning but also involves many various activities. Besides, from the findings, it is clear that the simile also appears in some of the most frequent contexts that require simile for more illustrations, as mentioned above. The exciting thing here is that the Vietnamese version prefers to use a complete set of similes, which means that compared, comparing, and comparative words are included.

\section{Acknowledgement}

The writer expresses thankfulness to anonymous reviewers for their recommendations and colleagues who always give essential support for feedback and suggestions during the study.

\section{References}

Azizah, W. (2019). The analysis of Similies in Harry Potter and the Sorcerer's Stone by JK Rowling. In Bogor English Student and Teacher (BEST) Conference, 1(1), 35-39.

Atieno, O. P. (2009). An analysis of the strengths and limitations of qualitative and quantitative 
research paradigms. Problems of education in the 21st century, 13(1), 13-18.

Bates, L., Lane, J., \& Lange, E. (1993) Writing clearly: Responding to student writing. Boston: Heinie.

Beidel, D. C., Frueh, C., \& Hersen, M. (2014). Adult psychopathology and Diagnosis (4th ed.). New Jersey: John Wiley \& Sons.

Bolaños Cuéllar, S. (2007). Source language text, paralell text, and model translated text: A pilot study in teaching translation. Forma y Función, (20), 225-252.

Carston, R., \& Wearing, C. (2011). Metaphor, hyperbole, and simile: A pragmatic approach. Language and Cognition, 3(2), 283-312.

Cassuto, L. (2018, May 28). On the Dissertation: How to Write the Introduction. The Chronicle of Higher Education. https://www.chronicle.com/article/On-theDissertation-How-to/243507.

Chanh, N. H. (2021). Aiding the translation process with affixal analysis - a case study in "The Old Man and The Sea”. Ho Chi Minh City University of Education Journal of Science, 18(4), 592-603.

Chanh, N. H. (2021). Students' perspectives in utilizing the affixation to learn English vocabulary: A case study at Can Tho University. Turkish Online Journal of Qualitative Inquiry. 12(3), 834-864.

Crowther, J. (ed.). (1992) Oxford advanced learner's dictionary. Encyclopedic edition. Oxford: Oxford University Press.

De Mendoza Ibáñez, F. J. R. (2020). Understanding figures of speech: Dependency relations and organizational patterns. Language \& Communication, 71(1), 16-38. https://doi.org/10.1016/j.langcom.2019.12.002

Fadaee, E. (2013). Translation techniques of figures of speech: A case study of George Orwells 1984 and Animal Farm. International Journal of English and Literature, 1(8), 174-181.

Genette, G. (1997). Paratexts: thresholds of interpretation. Cambridge: The University of Cambridge. pp. 1-2. ISBN 9781107784321. OCLC 867050409 . https://books.google.com.vn/books?id= AmWhQzemk2EC\&pg=PR18\&redir_esc=y\#v= onepage \&q\&f=false.

Geng, R., \& Wei, J. (2015) Application of the concept of defamiliarization in translation studies: Case studies of the translation of film titles. Journal of Language Teaching and Research, 7(1), 192-197.

Hamuddin, B., Syahdan, S., Rahman, F., Rianita, D., \& Derin, T. (2019). Do They Truly Intend to Harm Their Friends?: The Motives Beyond
Cyberbullying among University Students. International Journal of Cyber Behavior, Psychology and Learning (IJCBPL), 9(4), 32-44.

Hermans, T. (2003). Cross-cultural translation studies as thick translation. Bulletin of the School of Oriental and African Studies, University of London, 66(3), 380-389.

Hurford, J. R. \& Heasley, B. (1983). Semantics: a coursebook. Cambridge: Cambridge University Press.

Hurford, J. R. \& Heasley, B. (1983). Semantics: a coursebook. Cambridge: Cambridge University Press.

Kautsari, A. F. (2019). Techniques of translating Simile from English to Indonesian in Capote's breakfast at Tiffany's (Doctoral dissertation, UNNES).

Kandenan, E. (2017). Simile \& Metaphor in Translation: A Study on Students 'Translation of Amy Tan's-Two Kinds \| Short Story. Salatiga-Universitas Kristen Satya Wacana.

Kallet, Richard H.(2004). How to Write the Methods Section of a Research Paper. Respiratory Care 49 (October 2004), 49(10), 1229-1232.

Larson, M. L. (1984). Figurative propositions/metaphors and similes. In Meaningbased Translation: A Guide to Cross-language Equivalence, 246-255. Lanham, Mar. University Press of America.

Li, F., Ran, S., \& Xia, T. (2010). Translation of words with cultural image. Journal of Language Teaching and Research, 1(5), 694-700.

Maharani, S. A. I. (2016). Translation Strategy of Figure of Speech in Short Story. Lingual: Journal of Language and Culture, 2(2), 84-91.

Myers, G. (1994). Words in Ads. London: Edward Arnold.

Pierini, P. (2007). Simile in English: From Description To Translation. CÍRCULO de Lingüística Aplicada a la Comunicación (clac), 29(1), 21-43.

Putri, S. E., Hamuddin, B., Nursafira, M. S., \& Derin, T. (2020). Discourse Analysis in E-LearningBased Course Using Moodle Platform: An Experimental Design. REiLA: Journal of Research and Innovation in Language, 2(1), 1926.

Radich, Michael. (2020). A Student's Guide to Writing in East Asian Studies. (Cambridge, MA: Harvard University Writing n. d.), 35-37.

Reiss, K. (1971). Möglichkeiten und Grenzen der Übersetzungskritik. München: Max Hueber 
Verlag. Erroll F. Rhrodes (Trad. Ing.), (2000).

Translation Criticism -The potentials and Limitations. Categories and Criteria for Translation Quality Assessment. New York / Manchester, American Bible Society / St. Jerome Publishing.

Richards, J. \& Schmidt, R. (2010) Longman dictionary of language teaching and applied linguistics. Pearson Education Limited.

Sam, G., \& Catrinel, H. (2006). On the relation between metaphor and simile: When comparison fails. Mind \& Language, 21(3), 360-378.

Shi, X. (2014). The English Film Title Translation Strategies. Journal of Language Teaching \& Research, 5(3), 606-610.

Song, Y. (2020). Simile and Metaphor Interpretation in Children. English Language Teaching, 13(4), 91103.

Staiger, D. L. (2009). What Today's Students Need to Know about Writing Abstracts. International Journal of Business Communication January 3 (1966): 29-33; Swales, John M. and Christine B. Feak. Abstracts and the Writing of Abstracts. Ann Arbor, MI: University of Michigan Press

Starodedova, L. (2019). Problems of Poetic Translation in European Translation Studies. Journal of Danubian Studies and Research, 9(1), 305-315.

Szuchman, L. T., \& Thomlison, B. (2010). Writing with style: APA style for social work. Cengage Learning.

Thahara, Y. (2015). Translation Techniques of Simile in The Novel Angels \& Demons to Malaikat \& Iblis. Journal Online Universitas Abdurachman Saleh, 5(1), 9-21.

Wisnita, A. E. (2019). Metaphor and Simile in English Context: Do they know the differences? REiLA: Journal of Research and Innovation in Language, $1(2), 55-60$.

Zuba, J. (2016). Conclusion: Making Introductions. In The First Book: Twentieth-Century Poetic Careers in America (pp. 154-168). PRINCETON OXFORD: Princeton University Press. Retrieved from http://www.jstor.org/stable/j.ctt1dr359b.10. 